\title{
Development of FFF filaments for bone and teeth representation in 3D printed radiological objects
}

\author{
Savi, M. ${ }^{\mathrm{a}, \mathrm{b}}$; Andrade, M. A. B. ${ }^{\mathrm{a}}$; Villani, D. ${ }^{\mathrm{b}}$; Rodrigues Jr., O. ${ }^{\mathrm{b}}$ and Potiens, M. P. A. ${ }^{\mathrm{b}}$ \\ ${ }^{1}$ Instituto Federal de Santa Catarina - IFSC. 88020-300, Florianópolis - SC, Brazil \\ ${ }^{2}$ Instituto de Pesquisas Energéticas e Nucleares - IPEN. 05508-000. São Paulo-SP, Brazil. \\ matheus.savi@ifsc.edu.br and marco.bertoncini@ifsc.edu.br
}

\begin{abstract}
The use of 3D printing technologies is growing widely, including the possibility of designing phantoms for imaging and dosimetry. High attenuation tissues such as cortical bone, dentin and enamel need to be simulated to accurately produce 3D printed phantoms, especially for Fused Filament Fabrication (FFF) printing technology. A commercially available radiopaque FFF filament had been hard to find. This study aims to report, step-by-step, the development of a radiopaque FFF filament. A combination of radiopaque substances (Barium Sulfate - $\mathrm{BaSO}_{4}$ and $\mathrm{Calcium}$ Carbonate - $\mathrm{CaCO}_{3}$ ) were selected for use as fillers in an Acrylonitrile Butadiene Styrene (ABS) matrix and added in quantities calculated using the National Institute of Standards and Technology (NIST) XCOM tool. The filament was homogenized and characterized by analyzing its density and images obtained using Scanning Electron Microscopy (SEM), Computed Tomography (CT) and micro-CT ( $\mu$ CT) scans. Three filaments were produced with different Hounsfield Units (HU) equivalences: XCT-A (1607HU), XCT$\mathrm{B}(1965 \mathrm{HU})$ and XCT-C $(2624 \mathrm{HU})$ with respective densities of $1.166(6) \mathrm{g} / \mathrm{cm}^{3}, 1.211(2) \mathrm{g} / \mathrm{cm}^{3}$ and $1.271(3) \mathrm{g} / \mathrm{cm}^{3}$. With these values, high attenuation tissues, such as bones, dentine and enamel, can now be simulated with FFF 3D printing technology, at a low cost of production.
\end{abstract}

Keywords: 3D printing, Fused Filament Fabrication, Radiology, Phantom. 


\section{INTRODUCTION}

$3 \mathrm{D}$ printing is commonly used in many areas of industry and engineering to create parts and objects in an inexpensive way for the most varied applications. Since 1995 [1], the use of 3D printing as a way to simulate human body tissues in radiation field has been reported. Since then, many studies on materials and phantom fabrication using 3D printing technologies were done and evaluated by using ionizing radiation [2-5], especially for use in radiological imaging and dosimetry.

There are many techniques to 3D print an object, such as Stereolithography (SLA), Fused Filament Fabrication (FFF), Selective Laser Sintering (SLS) and Polyjet. FFF is also known as Fused Deposition Modeling (FDM) [6,7], is a common and low-cost method to do a 3D print. Some authors were successful in simulating human body with commercially available materials [8,9]. However, commercially available FFF filament materials capable of simulating tissues that exhibit high density and attenuation, compatible with bone, dentin and enamel, are hard to find. Although iron and other ferromagnetic materials have been used to simulate these tissues [10-12]; they have the intrinsic limitations of not being compatible with Magnetic Resonance (MRI) equipment if needed. Ferromagnetic materials are very abrasive to printing nozzles and some printing defects could occur while dual extruding it with another filament. For CT scans, HU values inside a given ROI could show high standard deviation, especially with high printing layer heights or narrow CT slices (under $2 \mathrm{~mm}$ thickness). This is caused by the difference of attenuation coefficients between adjacent tissues or materials, which could provoke heterogeneity and measurement uncertainties. The high attenuation Fe filament could also result in image artifacts similar to metallic implants.

Some of the commercially available printing filaments have already been evaluated in literature by reporting their response to radiation in terms of Hounsfield Unit (HU) equivalence of human tissues [13-15]. Savi et al. [16] reported that Polylactic Acid (PLA) with addition of copper reached the highest value of approximately $330 \mathrm{HU}$, which corresponds only to low limits of cortical bone, and is insufficient to represent dentin $(1600 \mathrm{HU}-2400 \mathrm{HU}[17,18])$ and enamel (above 2500HU [1820]) tissues. The literature and practice find that an approximately $350 \mathrm{HU}$ cortical bone value is only found in a few bones, like vertebrae. Cortical bone of long bones, such as femur, humerus or bones from skullcap, have values above $800 \mathrm{HU}$, even reaching $1600 \mathrm{HU}[17,19]$. Although other $3 \mathrm{D}$ printing 
technologies could achieve $800 \mathrm{HU}$ to over $1000 \mathrm{HU}[20,21]$, the cost of the $3 \mathrm{D}$ printer and its materials are different and considerably more expensive than FFF.

Some attempts on the development of radiopaque FFF filaments without ferromagnetic materials have been reported. For example, Hamedani et al [22] used a constant filament diameter of $1.75 \mathrm{~mm}$ using containing Barium Sulfate $\left(\mathrm{BaSO}_{4}\right)$. Despite successfully printing a radiopaque model, they could not achieve production. The recent work of Price et al [23] proposed a filament based on an ABS matrix doped with calcium titanate $\left(\mathrm{CaTiO}_{3}\right)$ that was homogenous and suitable for bone representation.

Considering this area is still underdeveloped and a documented step-by-step process could be useful to the scientific community, this paper aims to report the creation of a radiopaque filament to be used in FFF 3D printing technology testing a variety of dopant materials. Measurements were carried out to validate the conditions of simulating tissues with high HU values. Radiopaque substances with high atomic number were evaluated and, after selection, added to an Acrylonitrile Butadiene Styrene (ABS) filament matrix to realize the required radiopaque properties.

\section{MATERIALS AND METHODS}

A FFF filament is usually composed of two parts, a binder and a filler. The binder is made of a thermoplastic while the filler is composed of additive materials used to provide different properties to the resulting filament. The Acrylonitrile Butadiene Styrene - ABS TERLURAN GP 35 [24] from INEOS Styrolution was chosen as binder for the development of this filament, being the only binder available from the third-party filament manufacturer contracted to produce the filament with the required filler composition and concentration. Furthermore, ABS has similar characteristics to other commonly used binders (such as PLA and PETG). It has an excellent combination of mechanical, thermal, electrical and properties, as well as ease of processing. It also offers a good balance of resistance to impact, traction, hardness and modulus of elasticity [25]. Also, ABS surface can be chemically dissolved when in contact with acetone [26], a method that could be applied to correct external imperfections due to printing errors, or to adjust a more stable and strong fit when constructing a phantom with multiple parts that need to be socketed. 
Promising substances as fillers were selected based on anatomic mass (AM) from those available at the Federal Institute of Santa Catarina (IFSC). The addition of a high AM filler to the ABS binder increases the resultant attenuation to radiation giving radiopaque properties to the filament. Nonetheless, this resultant attenuation must be similar to high attenuation human tissues, otherwise the filament would behave as a barrier, making bone and teeth representations in radiological scans compromised.

To choice the filler was evaluated in terms of mass attenuation coefficient predicted using the NIST XCOM calculator [27] for peak and mean energy for RQT and RQR radiation qualities [28]. The choices were later compared to ICRU-44 [29] cortical bone attenuation. After selecting the materials, the process of mixing binder and filler was repeatedly conducted until a homogeneous filament was achieved with $1.75 \mathrm{~mm}$ in diameter and the selected concentration in weight.

\subsection{Selection of possible filler}

Many chemical substances available at IFSC chemistry laboratory were considered as possible filler, focusing on elements with high atomic number and its presentation as solid powder. Table 1 lists characteristics and cost for nine potential filler substances.

Table 1: Nine promising filler substances and their characteristics and relative prices.

\begin{tabular}{ccccc}
\hline Substance & Formula & $\begin{array}{c}\text { Molar mass } \\
(\mathrm{g} / \mathrm{mol})[30]\end{array}$ & $\begin{array}{c}\text { Density }\left(\mathrm{g} / \mathrm{cm}^{3}\right) \\
{[31,32]}\end{array}$ & $\begin{array}{c}\text { Price per kg } \\
\text { (USD) }\end{array}$ \\
\hline Calcium Carbonate & $\mathrm{CaCO}_{3}$ & 100.09 & 2.93 & $\$ 8.88$ \\
Barium Sulfate & $\mathrm{BaSO}_{4}$ & 233.38 & 4.94 & $\$ 10.92$ \\
Calcium Propionate & $\mathrm{C}_{6} \mathrm{H}_{10} \mathrm{CaO}_{4}$ & 186.22 & 1.38 & $\$ 89.41$ \\
Bismuth (III) Oxide & $\mathrm{Bi}_{2} \mathrm{O}_{3}$ & 465.96 & 8.9 & $\$ 220.24$ \\
Lead (II) Chloride & $\mathrm{PbCl}_{2}$ & 278.10 & 5.95 & $\$ 291.15$ \\
Copper (I) Chloride & $\mathrm{CuCl}_{\text {Red copper (I) Oxide }}$ & 98.99 & 4.14 & $\$ 348.90$ \\
Lead powder & $\mathrm{Cu}_{2} \mathrm{O}$ & 143.09 & 6.0 & $\$ 356.6$ \\
Copper (I) Iodate & $\mathrm{CuI}$ & 207.20 & 11.3 & $\$ 364.07$ \\
\hline
\end{tabular}


The predicted mass attenuation coefficients for a mixture of $90 \%$ ABS binder and $10 \%$ filler material was determined using NIST's XCOM tool for specific peak and mean energies for RQT and RQR radiation qualities. Figure 1 compares these coefficients with that of cortical bone from ICRU44. The $10 \%$ proportion was chosen as initial test, since the amount of filler directly influences the filament mechanical characteristic, making it brittle as its concentration rises. Hence, the material to be achieved needed to have a suitable attenuation at low concentrations, in order to make a filament of feasible use.

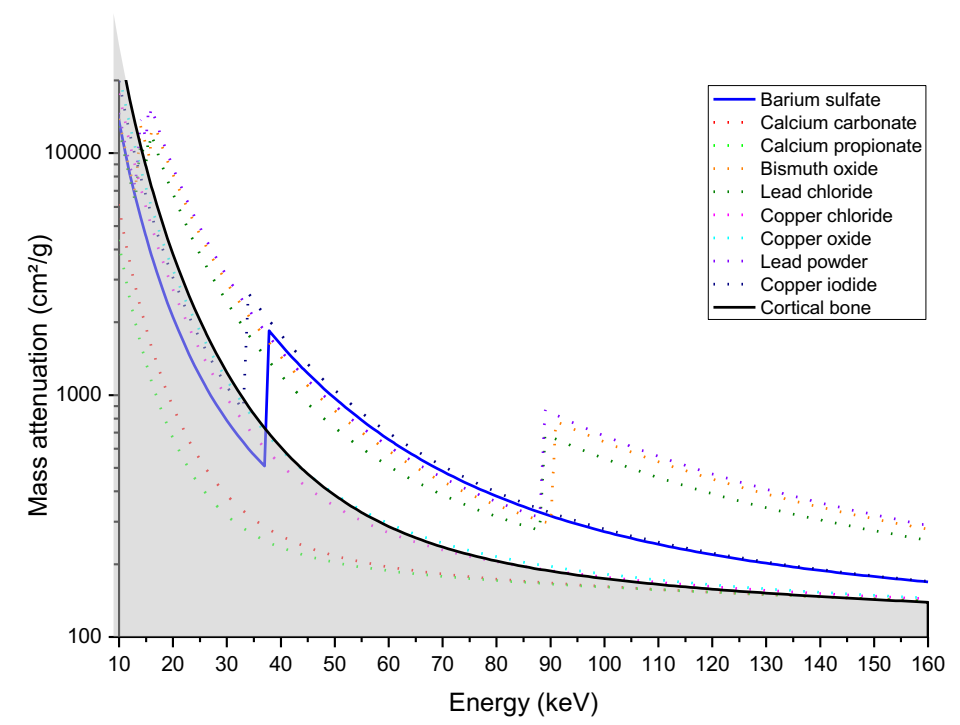

Figure 1: Mass attenuation coefficients of cortical bone (ICRU-44) and the nine promising substances, for diagnostic energy beam qualities.

Barium Sulfate $\left(\mathrm{BaSO}_{4}\right)$ was chosen as the filler substance because of its low cost and attenuation characteristics above that of cortical bone at energies above $37,5 \mathrm{kV}$, which provides a margin of corrections by reducing filler/binding ratio to approximate the resultant mass attenuation to the given cortical bone curve. By using this method of correction, all other substances with attenuation over cortical bone could be used as well, however, the price per kilogram of most of them were impracticable, as a kilogram filament final price below 100 USD is desired. One example is the Copper Oxide Red $\left(\mathrm{Cu}_{2} \mathrm{O}\right)$, which has an almost exact mass attenuation compatibility with ICRU's cortical bone, but being considerably expensive, it also makes it not interesting for filament fabrication. Substances below cortical attenuation were also excluded due to the need to increase the filler-to-binder ratio, which could interfere heavily in mechanical properties of the extruded filament. 


\subsection{Filament homogeneity}

Filament homogeneity, or lack of filler agglomeration in the raw filament, is evaluated primarily visually and later using a scanning electron microscope (SEM) and computed tomography scan technologies (CT and $\mu \mathrm{CT}$ ). During manufacture of filament samples, a dark color marked the binder while a lighter color designated the filler. Whenever large agglomeration of filler was observed, the batch of material was ground and re-extruded to eliminate defects. Homogeneity of each filament was determined by 3D printing $20 \times 20 \times 20 \mathrm{~mm} 3$ samples using a GTMax 3D Core H4 desktop printer with Simplify $3 D{ }^{\circledR}$ software selected with $100 \%$ infill in a $-45 /+45^{\circ}$ rectilinear pattern, $200 \mu$ m layer height and $0.4 \mathrm{~mm}$ nozzle. Each cube was scanned in a Philips Brilliance CT with 6 detector rows using $120 \mathrm{kVp}, 200 \mathrm{~mA}$, standard algorithm of volume, helicoidal acquisition and posterior standard axial reconstruction in $2 \mathrm{~mm}$ slices.

\subsection{SEM and $\mu \mathrm{CT}$ analysis}

The distribution of filler in the produced filaments was evaluated using Scanning Electron Microscopy (SEM) and Micro Computed Tomography ( $\mu \mathrm{CT})$. SEM was performed using a Hitachi Tabletop TM3000 microscope equipped with Electron Density Spectrometry (EDS), to identify which elements were present in the filament. The $\mu \mathrm{CT}$ was performed using a Zeiss Metroton 800 with $100 \mathrm{kV}, 21 \mu \mathrm{m}$ voxel size and gain of $2.5 \mathrm{x}$. Images were visualized using VGL Studio Software.

\subsection{Density measurements}

To perform density measurements, each raw filament analyzed had the mass $(m)$ of 5 samples, with $20 \mathrm{~mm}$ each, weighted in a precision scale and, to determine its volume $(v)$, the dimensions were measured in relation to water with a Hubbard pycnometer (Figure 2). Mass and volume values were acquired three times for each parameter. Each measurement was performed three times, to reduce uncertainties. The means and standard deviations were then calculated. 


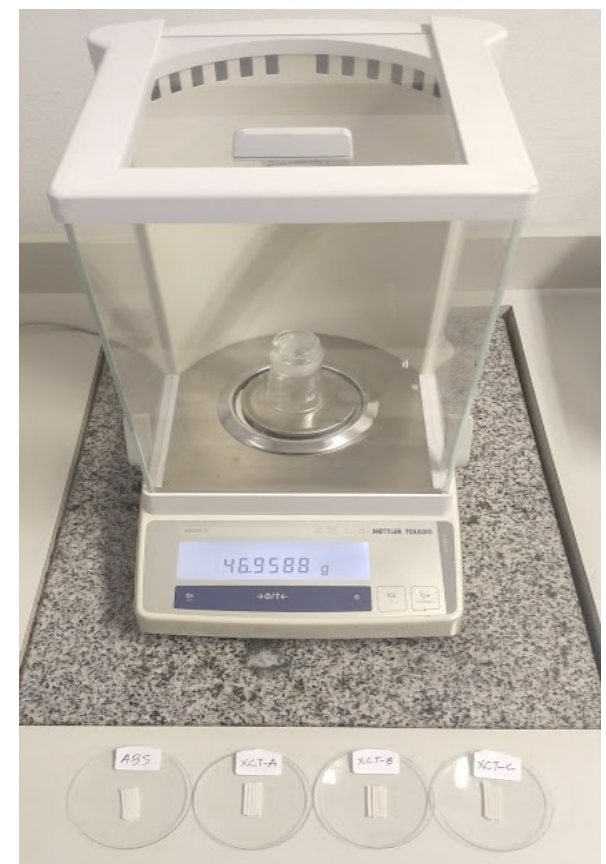

Figure 2: Samples, scale and Hubbard pycnometer (inside scale) used for density measurements.

The Equation 1 was used to determine the density $(\rho)$ of the samples, the uncertainties were propagated and its result given in $\mathrm{g} / \mathrm{cm}^{3}$, then compared with ICRP 110 Annex A [33].

$$
\rho=\frac{m}{v}
$$

\subsection{Hounsfield Unit (HU) equivalence}

A CT scan provides a three-dimensional voxel map of the tissue being imaged. The value of each voxel (CT number) in the image is determined by its gray scale representing the attenuation of x-rays passing through the voxel volume. The CT number is expressed in Hounsfield units (HU) and is a relation of the linear attenuation coefficient of the material $\left(\mu_{\text {material }}\right)$ in relation to the water $\left(\mu_{\text {water }}\right)$, where the value for water is defined equal to zero (Equation2) [34].

$$
H U=\frac{\mu_{\text {material }}-\mu_{\text {water }}}{\mu_{\text {water }}} \times 1000
$$

In order to analyze how the radiopaque filament produced would perform in terms of HU, five cubic samples with $100 \%$ infill were printed and scanned using the same set-up of topic 2.2. Each 
cube was evaluated using a region of interest (ROI) tool with $\sim 123 \mathrm{~mm}^{2}$, the values of mean $\mathrm{HU}$ and standard deviation (SD) were determined and a final HU mean with propagated uncertainties was calculated to know the highest mean HU value that each filament can achieve.

\section{RESULTS AND DISCUSSIONS}

The process involved in combining the binder to the elected filler occurs in the filament extruder, specifically in a molten section, where ABS pellets are melted between $215^{\circ} \mathrm{C}$ to $230{ }^{\circ} \mathrm{C}$ while the $\mathrm{BaSO}_{4}$ is added as a fine powder and carried by a thread. Before being added to the system, the powder has to be processed in a vibrating sieve to reduce the granulometry, dried for 24 hours and then vacuum sealed. As to the ABS, it is important that the pellet size is small as possible, making it easier to transport the $\mathrm{BaSO}_{4}$ powder homogeneously and increasing contact surface. The original pellets are oval white/pearl colored, and to reduce its size, a colored pure ABS filament was extruded, and later grounded until the pieces were smaller enough to better carry and mix with filler (Figure 3).

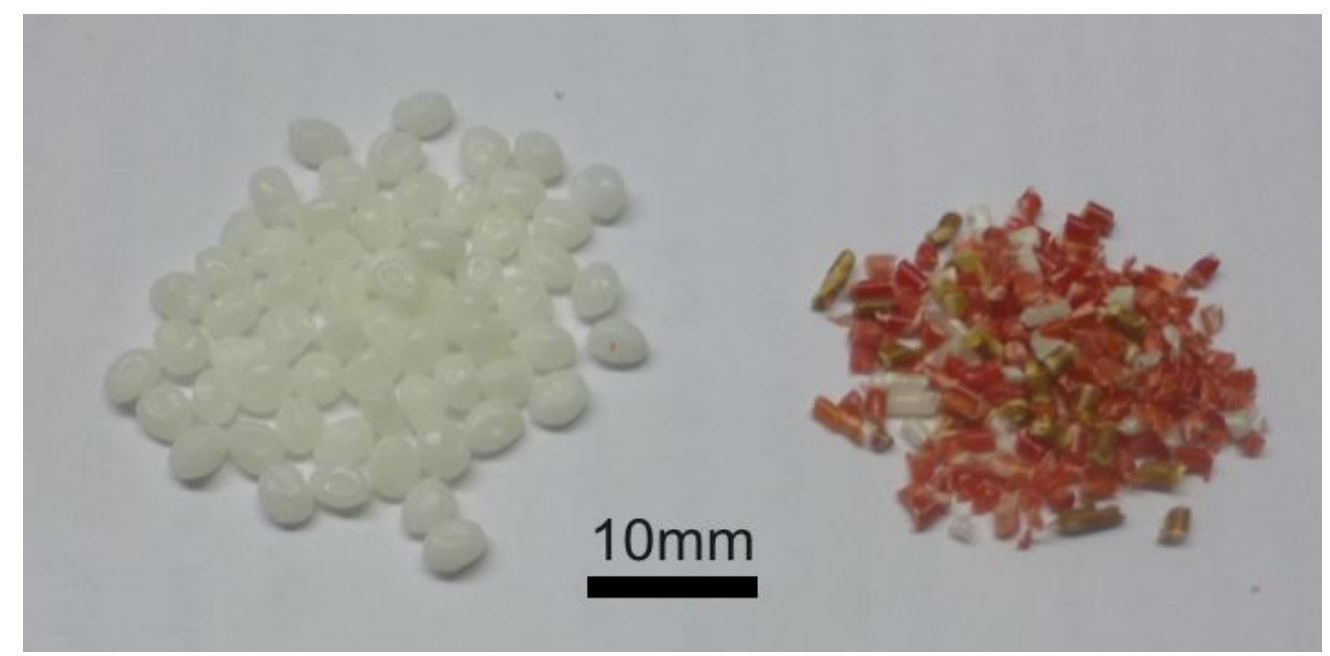

Figure 3: White/pearl ABS pellets (left) and the crushed colored ABS filament (right).

Figure 4-A illustrates the printed result of four extrusions of filament using $2.5 \%$ to $10 \%$ (in steps of $2.5 \%) \mathrm{BaSO}_{4}$ powder that produced an inhomogeneous material. The first problem was observed inside the molten section, where the single screw extruder is capable of carrying and mixing binder and filler until they become united, however, in an inhomogeneous way. Although a twin-screw extrusion would like improve homogeneity [35], it was unavailable at the time. The second problem 
observed was that the filler powder, when inside the transport extrusion mechanism, tends to agglomerate at the bottom of the pipe and in the thread carrying it, resulting in an inhomogeneous delivery to the molten $\mathrm{ABS}$ section of the extruder, creating uncertainty about the amount of $\mathrm{BaSO}_{4}$ present in the filament (Figure 4-B).
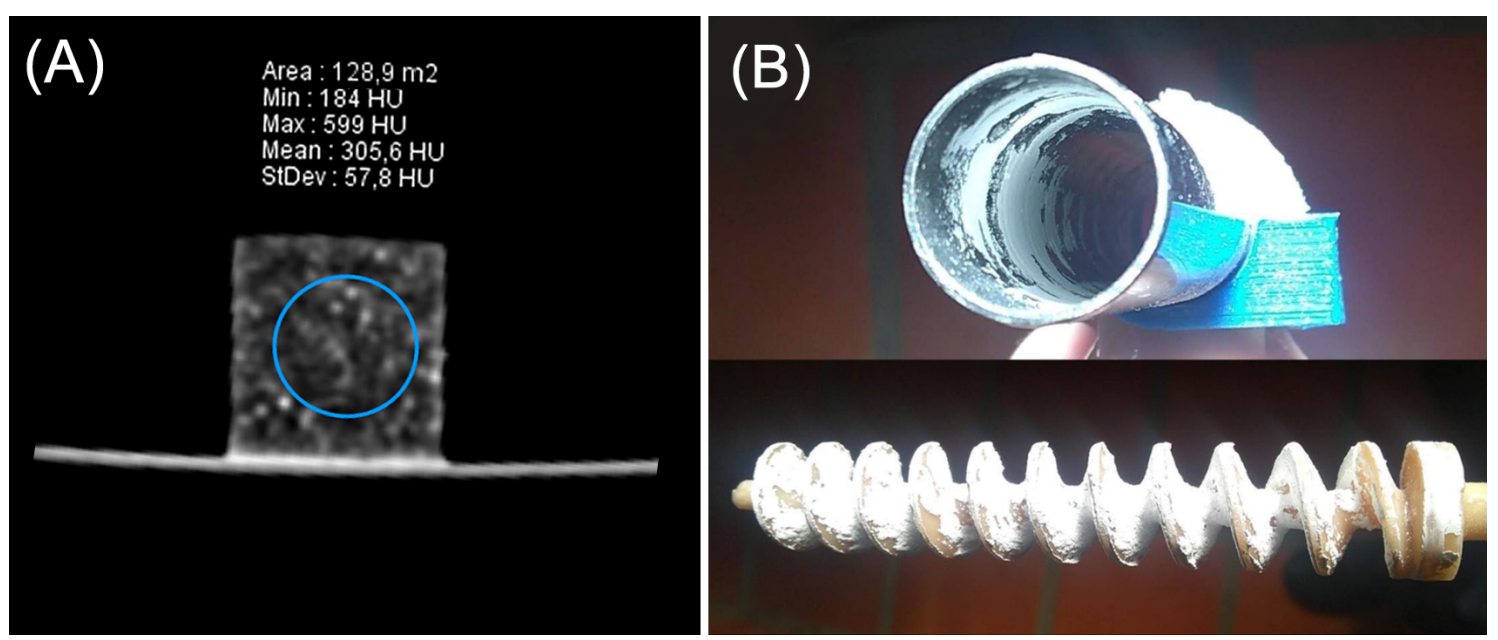

Figure 4: (A) poor homogeneity observed in initial CT tests, (B) agglomeration inside the transport pipe and in the screw.

To solve the lack of homogeneity due the single thread machinery, the filament was extruded, grounded in a crusher and then extruded again. After the first attempt, homogeneity and color changes could be visually detected, the filament color turned lighter as white specks of filler became scarcer and well distributed along the filament. This process was then repeated once for each batch of filament produced, in order to increase the effects observed. These steps provided a more homogeneous filament.

To reduce the $\mathrm{BaSO}_{4}$ agglomeration in the screw, another substance was added as filler, the Calcium Carbonate $\left(\mathrm{CaCO}_{3}\right)$. The $\mathrm{CaCO}_{3}$ powder reduces aggregation, but represents a friction and erosive problem, being a more abrasive substance to the extruder. By mixing both in a powdered form before being introduced in the extruder, the composite filler could be more easily delivered to the hotend with the molten ABS.

To determine the optimal ratio between $\mathrm{BaSO}_{4}$ and $\mathrm{CaCO}_{3}$, more mass attenuation coefficient data had to be taken in consideration. A new graph using the NIST XCOM Database, representing the attenuation behavior for eleven possible mixtures, is shown in Figure 5. All mixtures used a 90\% 
ABS and filler varied from $0 \% \mathrm{CaCO}_{3}$ and $10 \% \mathrm{BaSO}_{4}$ to $10 \% \mathrm{CaCO}_{3}$ and $0 \% \mathrm{BaSO}_{4}$, in steps of $1 \%$.

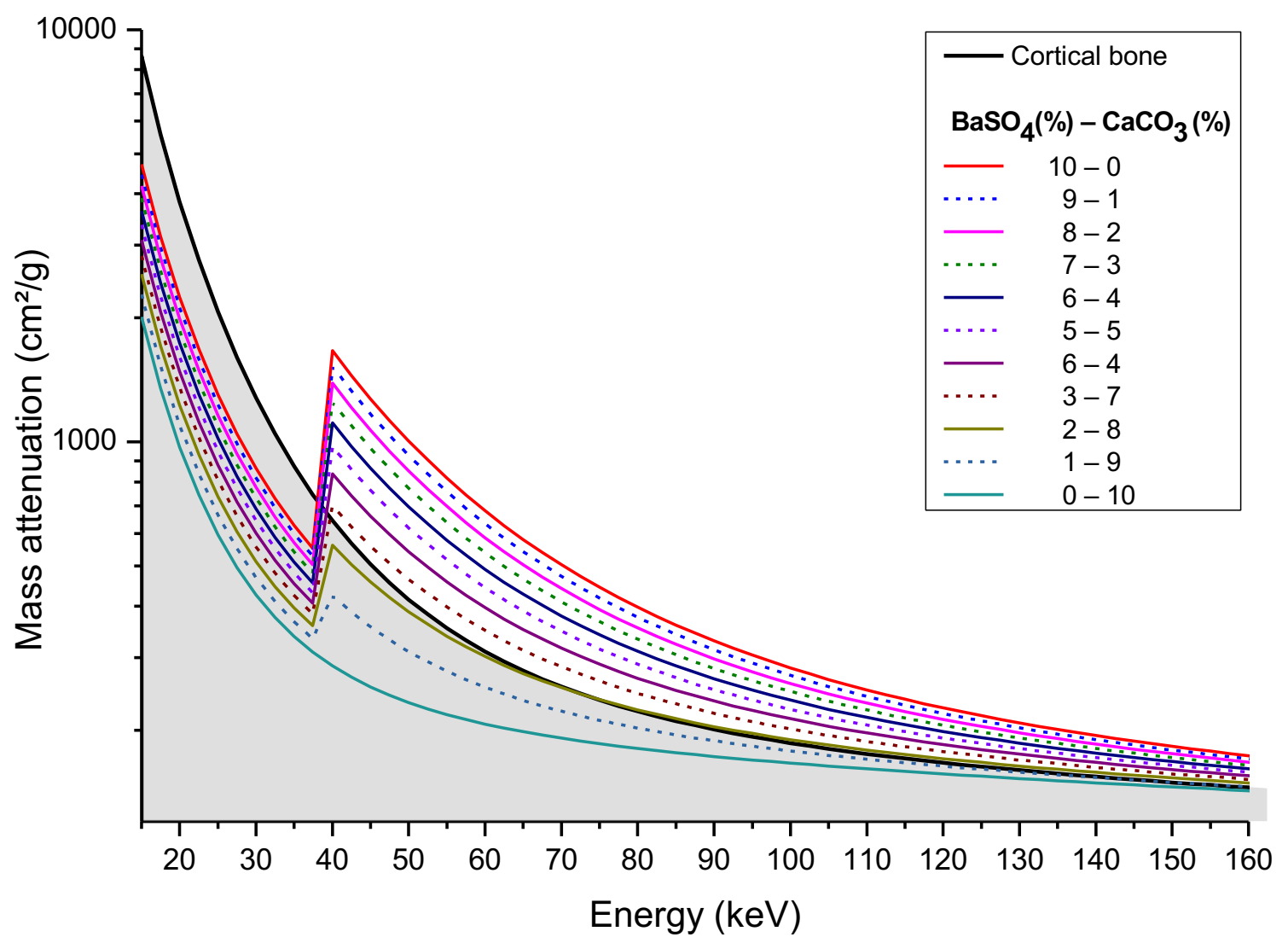

Figure 5: Calculated mass attenuation coefficients vs. energy for eleven filler proportions of $\mathrm{BaSO}_{4}$ and $\mathrm{CaCO}_{3}$, using XCOM.

Considering the desired attenuation for the filament, adding $\mathrm{CaCO}_{3}$ tends to diminish its final attenuation. To find a balanced ratio that permits a constant filler mixing without losing the radiopaque property, the five highest $\mathrm{BaSO}_{4}$ percentages (fig. 5) samples of powder filler mixture were sent for mixing and extrusion tests, executed by the filament manufacturer. The 70-30\% proportion for the $\mathrm{BaSO}_{4}-\mathrm{CaCO}_{3}$ filler in a $90 \% \mathrm{ABS}$ binder composition was chosen considering the need of a minimum amount of $\mathrm{CaCO}_{3}$ to permit a stable extrusion mechanically. Another reason, previously explained, concerns the possibility to correct the curve behavior when printed, as using smaller infill values tends to diminish the resultant attenuation. 
After determining filler composition, one more batch of filament was extruded, homogenized and identified as Filament A. An increase in filament homogeneity were visually detected when compared with the early extrusions without $\mathrm{CaCO}_{3}$ addition, mainly due to a more consistent and stable filler/binder ratio being transported and extruded. The filament became even lighter colored, and the filler specks were scarcer. Still, the addition of powder filler changes the mechanical properties of the ABS filament, making it more fragile on bending and breaking up more easily.

To confirm the internal homogeneity of Filament A, another set of samples with $20 \times 20 \times 20 \mathrm{~mm}^{3}$ were printed with $100 \%$ infill in a $-45 /+45$ rectilinear pattern, at a $200 \mu \mathrm{m}$ layer height. Each cube was scanned in a Philips Brilliance CT 6 channel tomography using $120 \mathrm{kVp}, 200$ $\mathrm{mA}$, standard algorithm to volume, helicoidal acquisition and posterior axial standard reconstruction in $2 \mathrm{~mm}$ slices.

Analyzing the scan, it was possible to check the resultant mean of $1000 \pm 21 \mathrm{HU}$, compatible with cortical bone, radiologically represented in CT scans with values above 250 HU. However, other denser tissues, like tooth dentin and enamel, could not be represented with Filament A. Also, the standard deviation found, $\cong 2 \%$ of the mean $\mathrm{HU}$, can quantitatively evidence radiological homogeneity.

Aiming to keep the first planned $\mathrm{BaSO}_{4}$ concentration of $10 \%$ and increase the $\mathrm{HU}$ range to represent denser human tissues, the composition of Filament A was modified by increasing $\mathrm{BaSO}_{4}$ and $\mathrm{CaCO}_{3}$ as listed on Table 2 to produce three different filaments named XCT-A, XCT-B and XCTC. All filaments were extruded with a constant $1.75 \mathrm{~mm}$ diameter and the same homogenization procedures previously described were applied. Proportionally, after each filler percentage increases, the mechanical properties diminish, turning it more fragile as the powder inside the plastic contributes to easily breaking up, when bending the filament in 90 degrees. However, the printing parameters were equal for pure and filler added ABS. After production, the three XCT filaments and a filament made of pure ABS were cut and evaluated in a precision scale and a Hubbard pycnometer. Results are also in Table 2.

Considering the density values of human tissues and organs on ICRP 110 Annex A, high density values of cortical bone (like humerus $\left.1.92 \mathrm{~g} / \mathrm{cm}^{3}\right)$ and teeth $\left(2.75 \mathrm{~g} / \mathrm{cm}^{3}\right)$ could not be achieved with any of the produced filaments, resulting in a material with different mechanical properties and matter interaction than the proposed mimicked tissues. On the other hand, pure ABS density is equal to 
breast gland and very close $\left(0.01 \mathrm{~g} / \mathrm{cm}^{3}\right.$ difference $)$ of many tissues like gallbladder, lymphatic nodes, prostate, salivary gland, among others.

Table 2: Radiopaque filaments created and its composition and density comparison in relation to ABS.

\begin{tabular}{|c|c|c|c|c|}
\hline \multirow{2}{*}{ Filament } & \multicolumn{3}{|c|}{ Composition (in mass) } & \multirow{2}{*}{ Density $\left(\mathrm{g} / \mathrm{cm}^{3}\right)$} \\
\hline & $\mathrm{BaSO}_{4}$ & $\mathrm{CaCO}_{3}$ & $\mathrm{ABS}$ & \\
\hline ABS & $0 \%$ & $0 \%$ & $100 \%$ & $1.020 \pm 0.000$ \\
\hline XCT-A & $10 \%$ & $4 \%$ & $86 \%$ & $1.166 \pm 0.006$ \\
\hline ХCT-B & $15 \%$ & $6 \%$ & $79 \%$ & $1.211 \pm 0.002$ \\
\hline XCT-C & $20 \%$ & $8 \%$ & $72 \%$ & $1.271 \pm 0.003$ \\
\hline
\end{tabular}

However, the fact that the filament mismatches density tissue is not an impediment, as it's desirable but not excluding. The material supposed to mimic the human tissue has its density equal or close to the one to be reproduced [36].

In an effort of know the attenuation theoretical behavior of the created filaments, NIST XCOM was used once more to compare ABS, cortical bone and XCT filaments, as shown in Figure 6.

In order to verify the distribution of filler among the binder matrix, two imaging techniques were used. Figure 7 (A)-(D) shows, respectively, ABS and XCT-A/B/C filaments in Scanning Electron Microscopy, while (F)-(I) shows it in the $\mu \mathrm{CT}$. It was possible to observe the absence of filler at the pure ABS and a gradual increase in quantity of filler as its concentration increases from XCT-A to C, especially observable in $\mu \mathrm{CT}$. As can be seen on SEM images, the quantity of filler agglomeration diminishes as the process of crushing filament and extruding it again occurs. Using Electron Density Spectroscopy (EDS), it was observed that the agglomerations seen on XCT A and B are made mainly by $\mathrm{BaSO}_{4}$ due its natural characteristic of agglomeration.

To evaluate Hounsfield unit equivalence and radiological tissue representation, five $20 \times 20 \times 20 \mathrm{~mm}$ samples were printed for each XCT filament, amounting 15 cubes. All samples were printed with a $100 \%$ infill, in an angular $-45^{\circ} / 45^{\circ}$ rectilinear pattern, and $200 \mu \mathrm{m}$ layer height. The XCT samples were then batch scanned in the CT (same setup described in section 2.1), having 
its mean HU values and standard deviation determined. These results can be found in Table 3 and the radiological analysis is shown in Figure 8.

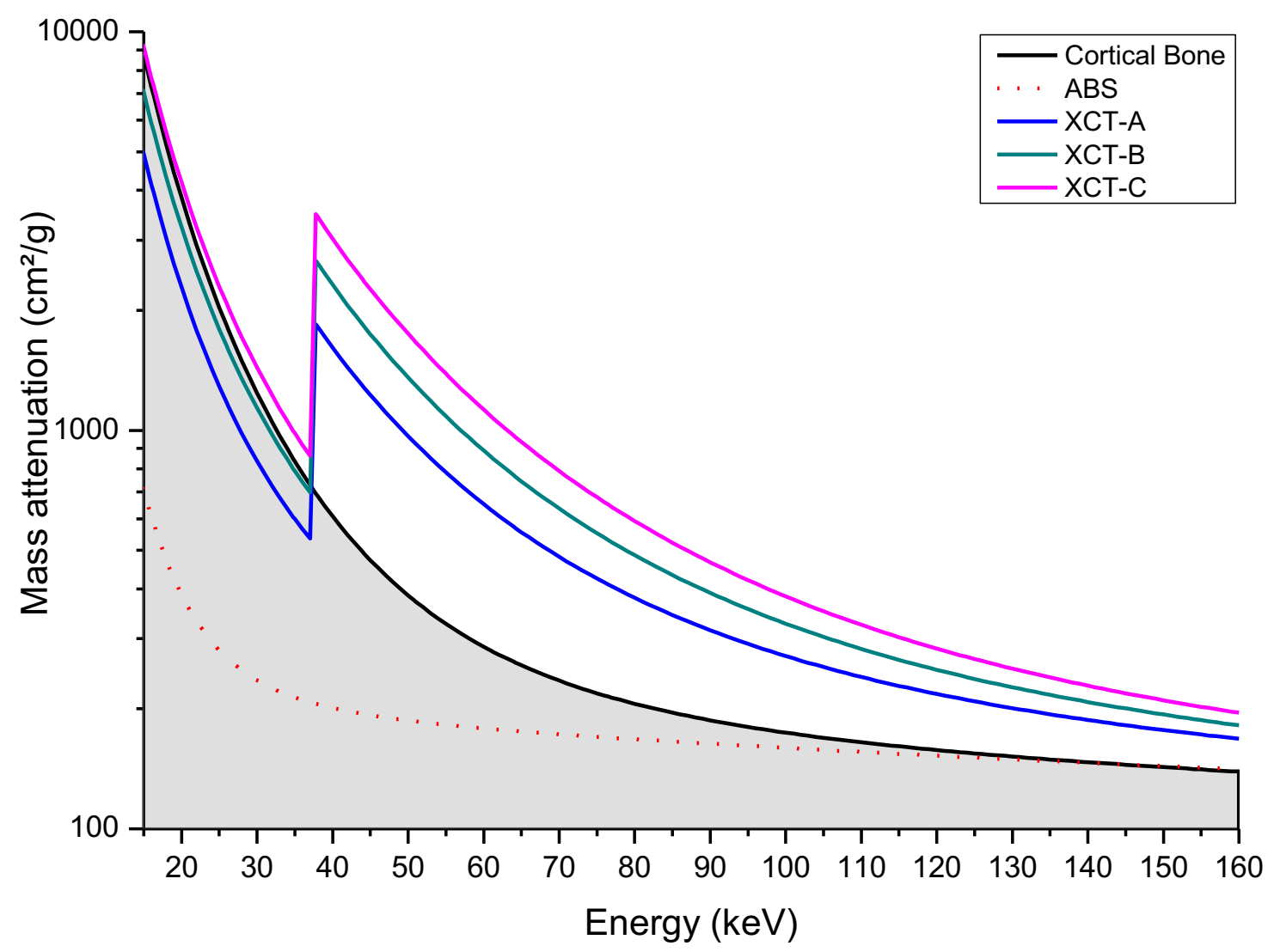

Figure 6: Theoretical attenuation behavior for ABS, XCT filaments and its comparison with ICRU44 cortical bone attenuation.

The three XCT filaments performed a long range of HU, opening a possibility of mimicking some denser human tissues. Cortical bone may be mimicked by XCT-A as the mean HU value of the filament is $1607 \mathrm{HU}$, with a propagated uncertainty of 23. Dentin can be also mimicked using XCTA or XCT-B, as its equivalence of mean HU value is 1965 , with a propagated uncertainty of 30 , is compatible.

Enamel, the natural human tissue with highest radiation attenuation, can be mimicked using XCT$\mathrm{C}$ and its highest mean value found on this paper was $2624 \mathrm{HU}$, with a propagated uncertainty of 50 . The standard deviation also confirms a considerable radiological homogenous material, whilst the 
filler powder could be barely visually discernible, with low HU uncertainties, as its maximum variation was $\cong 2 \%$.
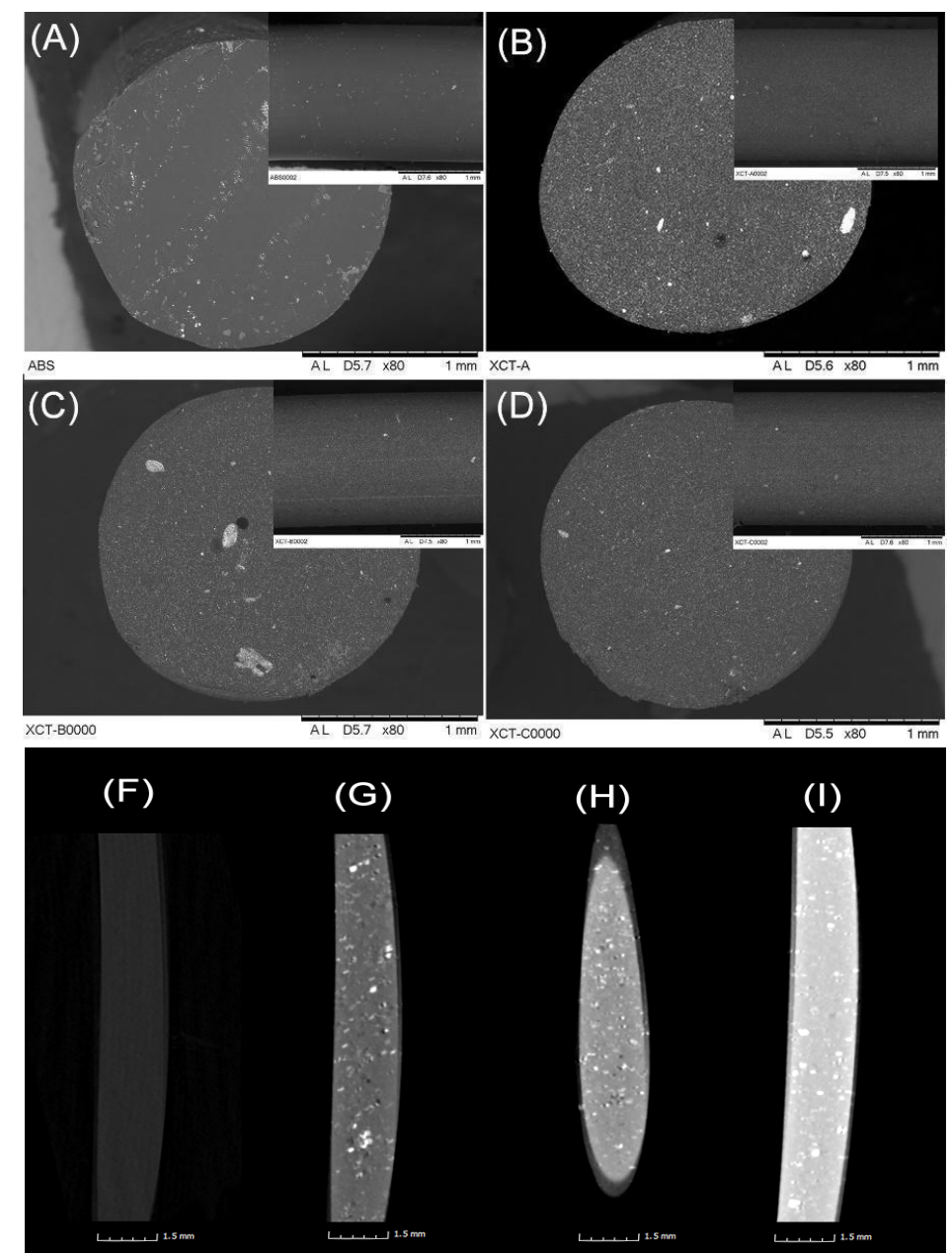

Figure 7: A-D scanning electron microscopy and (F-G) micro computed tomography of in sequence ABS, XCT-A, XCT-B and XCT-C

Predicting an assembly, the use of XCT-A for jaw bone, XCT-B for dentin and XCT-C for enamel would be realistic, as there will be three well discernible HU values mimicking three different attenuation regions. Uniting pure ABS filament [17], these four filaments when printed together, may enable the creation of 3D printed phantoms capable of mimicking a wide range of human tissues. Still, it is possible to correct the attenuation behavior (and in consequence the HU value) by changing the infill percentage of the 3D printed part and tests are needed to calibrate the printing parameters to match a specific CT setup. 
Table 3: Mean HU values and standard deviation for each 100\% infill XCT cubic sample.

\begin{tabular}{|c|c|c|c|c|c|}
\hline \multirow{2}{*}{$\begin{array}{l}\text { Sample } \\
\text { number } \\
\end{array}$} & XCT-A & \multicolumn{2}{|c|}{ ХCT-B } & \multicolumn{2}{|c|}{ XCT-C } \\
\hline & Mean SD & Mean & SD & Mean & SD \\
\hline 1 & 161320 & 1986 & 29 & 2644 & 57 \\
\hline 2 & 156223 & 1909 & 25 & 2535 & 42 \\
\hline 3 & 161529 & 1966 & 37 & 2636 & 44 \\
\hline 4 & 163123 & 2000 & 30 & 2662 & 52 \\
\hline 5 & 161320 & 1986 & 29 & 2644 & 57 \\
\hline Mean & 160726 & 1970 & 36 & 2624 & 50 \\
\hline
\end{tabular}

XCT-A HU mean values observed in table 3 are inside the cortical bone interval. Also, the standard deviation at all samples were also acceptable, as for dentin and enamel representations, XCT-B and C values are also inside the HU interval for those tissues, respectively.

The final price of the filament is a point of interest in this paper, which could diminish production costs and turn phantoms more available for developing countries. The XCT filaments had an equal or lower price of production, when compared with special $3 \mathrm{D}$ printing filaments. The cost of 1 kilogram of filament is estimated at 52 USD for XCT-A, 70 USD for XCT-B and 89 USD for XCTC. This considerable low price could aid the development of inexpensive radiological objects, as well as anthropomorphic phantoms and patient simulators.

\subsection{Research limitations}

This research reaches a goal creating filaments for hard tissue representations in FFF 3D printing technology. However, the final result may vary, as the filaments were tested in a single calibrated CT machine. Different CT equipment and/or acquisition parameters can find distinct HU values, but not enough to differ from a bone aspect.

High atomic number substances have a particular increase of attenuation behavior for low energies due to the k-edge peak of $\mathrm{BaSO}_{4}$, which changes the resulting spectrum in theoretical calculations. If one intends to use these filaments at energies other than $\mathrm{CT}$, further testing is required 
to observe how the filament will respond as a result of the interaction of $\mathrm{BaSO}_{4}$ at these energies, the proportion of photoelectric effect and Compton scattering should change and interact with the detector differently.

At this moment, it's possible to affirm that the XCT filaments are suitable for mimicking bone, dentin and enamel for CT imaging phantoms. To consider the created filaments as tissue-equivalents, a larger characterization should be made, as the information here presented are not enough to affirm that property as valid.

\section{CONCLUSIONS}

Although there are other recent $3 \mathrm{~d}$ printing methods for high density representations of the human body, the idea needed to be improved to solve some problems reported in literature [10-13]. The solution presented in this paper uses a different approach, by using inexpensive nonmetallic filler to compose a filament that could print high density anatomies without double extrusion. ABS was used as base with addition of $\mathrm{BaSO}_{4}$ and $\mathrm{CaCO}_{3}$ to increase radiopaque properties and to solve mechanical problems due to inconsistent extrusion, respectively. Techniques like $\mu \mathrm{CT}$, SEM, pycnometry and CT were used to initially evaluate the filaments created and to determine quantities as density and Hounsfield units, in order to verify which tissues could be mimicked using the XCT filament in FFF $3 \mathrm{D}$ printing. High density tissues, as the cortical portion of long bones, dentin and enamel, can be reproduced in $3 \mathrm{D}$ printed phantoms, using any simple FFF $3 \mathrm{~d}$ printing machines.

This product was tested, validated and should allow the development of custom cheaper radiological imaging phantoms than the ones commercially available.

\section{OTHER INFORMATION}

The XCT filaments are a property of Federal Institute of Santa Catarina - Brazil, with patent pending registered under number BR1020190245077. 


\section{ACKNOWLEDGMENT}

The authors would like to thank Research Directorship of IFSC - Campus Florianopolis and ProRectory of Research and Innovation of IFSC for the funding. Also, a thanks to IPEN, CAPES, FAPESP (PROJECT 2017/50332-0) and CNPq (PROJECT 312131/2016-0 and process number 42098/2017-5) for their support. An especial thanks must be given to Instituto SENAI de Inovação em Manufatura Avançada e Microfabricação and the collaborators Cristiano Cardoso and Gleicy Ribeiro for the $\mu \mathrm{CT}$ scan.

\section{REFERENCES}

[1] MANKOVICH, N. J.; LAMBERT, T.; ZRIMEC, T.; HILLER, J. B. Anatomic vascular phantom for the verification of MRA and XRA visualization and fusion. Med Imaging 1995: Physiol Funct from Multidimens Images, v. 2433, p.73, 1995. https://doi.org/10.1117/12.209724.

[2] ALSSABBAGH, M.; TAJUDDIN, A. B.; MANAP, M. A. Evaluation of nine 3D printing materials as tissue equivalent materials in terms of mass attenuation coefficient and mass density. Int $\mathbf{J}$ Adv Appl Sci, v. 4, p. 168-73, 2017. https://doi.org/10.21833/ijaas.2017.09.024.

[3] IVANOV, D.; BlizNAKOVA, K.; BUlieV, I.; POPOV, P.; METTIVIER, G.; RUSSO, P.; DI LILLO, F.; SARNO, A.; VIGNERO, J.; BOSMANS, H.; BRAVIN, A.; BLISKANOV, Z. Suitability of low density materials for 3D printing of physical breast phantoms. Phys Med Biol, v.63, n. 175020, 2018. https://doi.org/10.1088/1361-6560/AAD315.

[4] GEAR, J. I.; CUMMINGS, C.; CRAIG, A. J.; DIVOLI, A.; LONG, C. D. C.; TAPNER, M.; FLUX, G. D. Abdo-Man: a 3D-printed anthropomorphic phantom for validating quantitative SIRT. EJNMMI Phys, v. 3, n.17, 2016. https://doi.org/10.1186/s40658-016-0151-6.

[5] NIEBUHR, N. I.; JOHNEN, W.; GÜLDAGLAR, T.; RUNZ, A.; ECHNER, G.; MANN, P.; MÖHLER, C.; PFAFFENBERGER, A.; JÄKEL, O.; GREILICH, S. Technical Note: Radiological properties of tissue surrogates used in a multimodality deformable pelvic phantom for MR-guided radiotherapy. Med Phys, v. 43, p. 908-916, 2016. https://doi.org/10.1118/1.4939874.

[6] SCULPTEO. The state of 3D printing. Ed 2018. p. 1-30. Avaliable at: https://info.sculpteo.com/thestate-of-3d-printing-2018.

[7] TAPPA, K.; JAMMALAMADAKA, U. Novel Biomaterials Used in Medical 3D Printing Techniques. J Funct Biomater, v. 9, n. 1, 2018. https://doi.org/10.3390/jfb9010017.

[8] KIARASHI, N.; RAVIN, C. E.; NOLTE, A.C.; STURGEON, G. M.; SEGARS, W. P.; NOLTE, L. W.; LO, J. Y. Development of realistic physical breast phantoms matched to virtual breast phantoms based on human subject data; Development of realistic physical breast phantoms matched to virtual breast phantoms based on human subject data. Med Phys, v. 42, n.7, p.4116-4126, 2015. 
https://doi.org/10.1118/1.4919771.

[9] SHEN, S.; ZHAO, Z.; WANG, H.; HAN, Y.; DONG, E.; LIU, B.; LIU, W.; CROMEENS, B.; ADLER, B.; BESNER, G.; RAY, W.; HOEHNE, B.; XU, R. Freeform fabrication of tissue-simulating phantoms by combining three-dimensional printing and casting. Des Qual Biomed Technol IX, v. 9700, p.970009-1-97009-6, 2016 . https://doi.org/10.1117/12.2212305.

[10] BECKMANN, J.; POPOVIC, K. Assessment of the attenuation of metal-infused filaments for 3D printing a gamma camera calibration phantom. Med Eng Phys, v. 80, p. 60-64, 2020. https://doi.org/10.1016/J.MEDENGPHY.2020.04.003.

[11] TINO, R.; YEO, A.; BRANDT, M.; LEARY, M.; KRON, T. The interlace deposition method of bone equivalent material extrusion 3D printing for imaging in radiotherapy. Mater Des, v. 199, 2021. https://doi.org/10.1016/j.matdes.2020.109439.

[12] CEH, J.; YOUD, T.; MASTROVICH, Z.; PETERSON, C.; KHAN, S.; SASSER, T. A.; SANDER, I. M.; DONEY, J.; TURNER, C.; LEEVY, W. M. Bismuth infusion of ABS enables additive manufacturing of complex radiological phantoms and shielding equipment. Sensors (Switzerland), v. 17, p.1-11, 2017. https://doi.org/10.3390/s17030459.

[13] AlsSABBAGH, M.; TAJUdDIN, A. A.; ABDULMANAP, M.; ZAINON, R. Evaluation of 3D printing materials for fabrication of a novel multi-functional 3D thyroid phantom for medical dosimetry and image quality. Radiat Phys Chem 2017, v. 135, p.106-112, 2017. https://doi.org/10.1016/j.radphyschem.2017.02.009.

[14] SHIN, J.; SANDHU, R. S.; SHIH, G. Imaging Properties of 3D Printed Materials: Multi-Energy CT of Filament Polymers. J Digit Imaging, v. 30, p. 572-575, 2017. https://doi.org/10.1007/s10278-0179954-9.

[15] DANCEWICZ, O. L.; SYLVANDER, S. R.; MARKWELL, T. S.; CROWE, S.B.; TRAPP, J. V. Radiological properties of 3D printed materials in kilovoltage and megavoltage photon beams. Phys Medica, v. 38, p. 111-118, 2017. https://doi.org/10.1016/J.EJMP.2017.05.051.

[16] SAVI, M.; ANDRADE, M. A. B.; POTIENS, M. P. A. Commercial filament testing for use in 3D printed phantoms. Radiat Phys Chem, v. 174, 2020. https://doi.org/10.1016/J.RADPHYSCHEM. 2020.108906.

[17] RESNIK, R.; KIRCOS, L. T.; MISCH, C. Diagnostic Imaging and Techniques In: Contemporary Implant Dentistry. $3^{\text {rd }}$ ed. St. Louis: Mosby Elsevier; 2007. p. 38-67.

[18] SAKUMA, A.; SAITOH, H.; MAKINO, Y.; INOKUCHI, G.; HAYAKAWA, M.; YAJIMA, D.; IWASE, H. Three-dimensional visualization of composite fillings for dental identification using CT images. Dentomaxillofacial Radiol, v. 41, p. 515-519, 2012. https://doi.org/10.1259/dmfr/13441277.

[19] BORGES, M. S.; MUCHA, J. N. Bone density assessment for mini-implants position. Dental Press J Orthod, v. 15, p. 58-60, 2010.

[20] HAZELAAR, C.; VAN EIJNATTEN, M.; DAHELE, M.; WOLFF, J.; FOROUZANFAR, T.; SLOTMAN, B.; VERBAKEL, W. F. A. R. Using 3D printing techniques to create an anthropomorphic thorax phantom for medical imaging purposes. Med Phys, v. 45, p. 92-100, 2018. https://doi.org/10.1002/mp.12644.

[21] LI, Y.; LI, Z.; AMMANUEL, S.; GILLAN, D.; SHAH, V. Efficacy of using a 3D printed lumbosacral 
spine phantom in improving trainee proficiency and confidence in CT-guided spine procedures. 3D Print Med, v. 4, 2018. https://doi.org/10.1186/s41205-018-0031-x.

[22] HAMEDANI, B. A.; MELVIN, A.; VAHEESAN, K.; GADANI, S.; PEREIRA, K.; HALL, A. F. Three-dimensional printing CT-derived objects with controllable radiopacity. J Appl Clin Med Phys, v. 19, p. 317-328, 2018. https://doi.org/10.1002/acm2.12278.

[23] PRICE, G.; BIGLIN, E. R.; COLLINS, S.; AITKINHEAD, A.; SUBIEL, A.; CHADWICK, A. L.; CULLEN, D. M.; KIRKBY, K. J.; SCHETTINO, G.; TIPPING, J.; ROBINSON, A. An open source heterogeneous 3D printed mouse phantom utilising a novel bone representative thermoplastic. Phys Med Biol, v. 65, 2020. https://doi.org/10.1088/1361-6560/ab8078.

[24] INEOS STYROLUTION. Technical datasheet: Terluran GP-35. 2016. Avaliabe at: https://www.ineos-styrolution.com/INTERSHOP/web/WFS/Styrolution-Portal-Site/en_US/-

/USD/ViewPDF-Print.pdf?SKU=300600120829\&RenderPageType=ProductDetail.

[25] THREEPOPNATKUL, P.; TEPPINTA, W.; SOMBATSOMPOP, N. Effect of co-monomer ratio in ABS and wood content on processing and properties in wood/ABS composites. Fibers Polym, v. 12, n. 8, p.1007-1013, 2011. https://doi.org/10.1007/S12221-011-1007-2.

[26] MCCULLOUGH, E.J.; YADAVALLI, V. K. Surface modification of fused deposition modeling ABS to enable rapid prototyping of biomedical microdevices. J Mater Process Technol, v. 213, n. 6, p. 947-954, 2013. https://doi.org/10.1016/j.jmatprotec.2012.12.015.

[27] BERGER, M. J.; HUBBELL, J. H.; SELTZER, S. M.; CHANG, J.; COURSEY, J. S.; SUKUMAR, R.; ZUCKER, D. S.; OLSEN, K. XCOM: Photon Cross Section Database (version 1.5), 2010.

[28] PHYSIKALISCH-TECHNISCHE BUNDESANSTALT. Radiation qualities used for studies in radiation protection, 2015.

[29] WHITE, D. R.; BOOZ, J.; GRIFFITH, R. V.; SPOKAS J. J.; WILSON, I. J. Report 44. J Int Comm Radiat Units Meas. v. os23, n. 1, 1989. https://doi.org/10.1093/jicru/os23.1.report44.

[30] KIM, S.; CHEN, J.; CHENG, T.; GINDUlYTE, A.; HE, J.; HE, S.; LI, Q.; SHOEMAKER, B. A.; THIESSEN, P. A.; YU, B.; ZASLAVSKY, L.; ZHANG, J.; BOLTON, E. E. PubChem 2019 update: Improved access to chemical data. Nucleic Acids Res, v. 47, n. D1, p. 1102-1109, 2019. https://doi.org/10.1093/nar/gky1033.

[31] VALOR, A.; REGUERA, E.; SÁNCHEZ-SINENCIO, F. Synthesis and X-ray diffraction study of calcium salts of some carboxylic acids. Powder Diffr, v. 17, p. 13-18, 2002. https://doi.org/10.1154/ 1.1414011 .

[32] HAYNES, W. M. CRC Handbook of Chemistry and Physics. 93 ${ }^{\text {rd }}$ ed. CRC Press; 2012.

[33] ICRP. International Comission on Radiation Protection, Report 110: Annexes A-D. v. 39, p. 47 -70, 2009. https://doi.org/10.1016/j.icrp.2009.07.005.

[34] HSIEH, J. Computed Tomography: Principles, Design, Artifacts, and Recent Advances. $2^{\text {nd }}$ ed. Bellingham: Spie, 2009. Avaliable at: https://spie.org/Publications/Book/2049426?SSO=1.

[35] TODD, D. B. Improving incorporation of fillers in plastics. A special report. Adv Polym Technol, v. 19, p. 54-64, 2000. https://doi.org/10.1002/(SICI)1098-2329(20000117)19:1<54::AID-ADV6>3.0. CO;2-\#. 
[36] XU, X. G.; ECKERMAN, K. F. Handbook of anatomical models for radiation dosimetry. $1^{\text {st }}$ ed. Boca Raton: CRC Press, 2010. 